\title{
Self-controlled feedback enhances learning in adults with Down syndrome
}

\author{
Feedback autocontrolado melhora a aprendizagem em adultos com síndrome \\ de Down
}

Suzete Chiviacowsky', Gabriele Wulf², Camila Machado', Nels Rydberg²

\begin{abstract}
Background: One factor that has consistently been shown to enhance learning in typical participants is self-controlled practice. Objectives: The purpose of the present study was to examine whether the learning benefits of self-controlled feedback found previously in non-disabled adults would also be found in adults with Down syndrome. Methods: Participants with Down syndrome practiced a linear positioning task. In the self-control group, learners were provided with feedback about the movement outcome at their request. Each participant in the yoked group received the same feedback schedule as their counterpart in the self-control group. Results: Learning was assessed by a retention test, consisting of 10 trials without feedback, one day later. The self-control group demonstrated more effective learning of the task than the yoked group. Conclusion: Self-controlled feedback enhanced motor learning in participants with Down syndrome.
\end{abstract}

Keywords: physical therapy; motor learning; autonomy; intellectual disability; linear positioning.

\section{Resumo}

Contextualização: Uma variável que consistentemente tem mostrado melhorar a aprendizagem em sujeitos típicos é a prática autocontrolada. Objetivos: Examinar se os benefícios do feedback autocontrolado para a aprendizagem, encontrados previamente em adultos típicos, também serão encontrados em adultos que apresentam a Síndrome de Down. Métodos: Participantes com a Síndrome de Down praticaram uma tarefa de posicionamento linear. Os aprendizes do grupo autocontrolado receberam feedback sobre o resultado do movimento, quando solicitado. Já os participantes do grupo pareado receberam o mesmo arranjo de feedback dos sujeitos do grupo autocontrolado. Resultados: A aprendizagem foi avaliada por meio de um teste de retenção, o qual consistiu em dez tentativas sem feedback, um dia depois da fase de prática. O grupo autocontrolado demonstrou aprendizagem mais efetiva da tarefa do que o grupo pareado. Conclusão: Feedback autocontrolado melhora a aprendizagem motora em sujeitos com a Síndrome de Down.

Palavras-chave: fisioterapia; aprendizagem motora; autonomia; incapacidade intelectual; posicionamento linear.

Received: 03/25/2011 - Revised: 10/18/2011 - Accepted: 01/11/2012

\footnotetext{
School of Physical Education, Universidade Federal de Pelotas (UFPEL), Pelotas, RS, Brazil

${ }^{2}$ Department of Kinesiology, University of Nevada (UNLV), Las Vegas, NV, USA

Correspondence to: Suzete Chiviacowsky, Escola Superior de Educação Física, Universidade Federal de Pelotas, Rua Luís de Camões, 625, CEP 96055-630, Pelotas, RS, Brasil,

e-mail: schivi@terra.com.br
} 


\section{Introduction $: \therefore$.}

Approximately $0.3 \%$ of human conceptions present Down syndrome (DS), which is caused by trisomy of human chromosome $21^{1}$. Significant changes in the architecture and functioning of the central nervous system result from this extra chromosome. DS is associated with changes in the anatomy of the body (i.e., low height, short extremities, short digits, and tendency towards obesity), resulting in atypical movement patterns ${ }^{2}$. Also, perceptual-motor competence in children with DS is generally delayed, when compared with children without $\mathrm{DS}^{3}$.

Skilled movement is fundamental to human experience. Yet, few studies have been concerned with motor learning in persons with DS. There are some indications that, with specific training programs, people with DS can improve their performance of tasks involving, for example, balance ${ }^{4}$ or reaction time $^{5}$ - sometimes to a level that is similar to that of typical individuals ${ }^{6}$. In the context of treatments for motor speech disorders, which are frequently seen in people with DS, the effects of augmented (visual or auditory) feedback have been examined. Improvements in the accuracy of speech production were found in children and teenagers with DS when visual feedback (based on electropalatography) was provided to participants ${ }^{7,8}$. In another study related to motor learning, the effects of different feedback frequencies (100\% and 33\%) were examined in adults with DS learning a simple aiming task 9 The results showed that the reduced frequency (33\%) was as effective as feedback after every trial (100\%) (i.e., resulted in similar learning), although not more effective, as has been the case in many studies with non-disabled participants ${ }^{10}$.

One factor that has consistently been shown to enhance the learning of motor skills in typical participants is self-controlled practice. Research related to perceptions of self-efficacy ${ }^{11,12}$, selfregulated learning strategies ${ }^{13,14}$, and educational learning ${ }^{15}$ has revealed that allowing learners to use their own strategies in a self-controlled practice context increases their ability to perform and learn. In the motor learning domain, numerous studies with young or older adults, as well as children, have demonstrated more effective learning under self-controlled conditions relative to yoked practice conditions ( for a review, see Wulf ${ }^{16}$ ). Studies examining effects of self-controlled practice typically involve yoked control groups. For example, if the variable under investigation is feedback, each participant in a self-control group is yoked to a participant in the yoked group, such that the yoked counterpart receives feedback on the same trials on which the respective self-control learner had requested feedback (e.g., Trials $1,3,4,7$, etc.). The purpose of this procedure is to control for the amount and scheduling of feedback or whichever variable is under the learner's control. Several studies found benefits of self-controlled feedback schedules ${ }^{17-19}$. Learning advantages have also been shown for other types of self-controlled practice, such as the self-controlled use of physical assistive devices ${ }^{20,21}$, or giving the learners the opportunity to decide when to watch a video model of a skilled performer ${ }^{22}$. However, to our knowledge, the influence of practice conditions that promote self-control has not yet been examined in individuals with DS.

A potentially limiting factor in the generalizability of the self-control benefit for learning is the intellectual disability of this population. DS has been associated with memory impairments ${ }^{23}$, weakness in verbal working memory ${ }^{24}$, and slower reaction times ${ }^{25}$, reflecting limitations in the information processing speed ${ }^{26}$. Persons with DS also appear to have fewer attentional resources available to process additional information, as more attentional capacity is necessary to monitor basic aspects of motor performance as a result of less optimal movement control ${ }^{27}$. In a study examining the processing of visual feedback in goal-directed movements in adults with DS, Hodges et al. ${ }^{28}$ showed that participants with DS exhibited longer movement times than participants without DS, suggesting that persons with DS are either more dependent on response-produced feedback, or that they require more time to process feedback. These findings might suggest that people with DS could be overwhelmed by the additional task demand of having to make decisions about the delivery of feedback, which could potentially hinder the learning process. Alternatively, the autonomy experienced by learners under self-controlled practice conditions may satisfy a fundamental psychological need, which has been shown to be associated with optimal functioning and learning in a broad range of domains ${ }^{29,30}$.

Examining how motor skill learning can be enhanced in persons with DS is not only of theoretical interest, but may also have important practical implications for the lives of those affected by DS. Given the ostensibly powerful learning effects of self-controlled practice conditions - that provide learners with a certain degree of autonomy - seen in typical adults and children ${ }^{17,31,32}$, we wanted to examine whether similar learning advantages would be found in participants with DS. We predicted that self-controlled practice, in particular the ability to choose when to receive feedback, would result in more effective learning compared to a practice condition without this opportunity (yoked group). The task required participants to move a slide on a track from a starting position to a target position. One group received feedback about the accuracy of their movements at their request, while another (yoked) group of participants received feedback after the same trials as their counterparts in the self-control group, but had no control over the feedback schedule. Learning was assessed in a retention test without feedback one day after the practice phase. 


\section{Methods : $:$.}

\section{Participants}

Thirty adults (14 men and 16 women), all right-handed, ranging in age from 18 to 29 years (mean age: 21.7; SD: 2.88) participated in the present study. They were recruited from schools for individuals with DS. The self-control group ranged in age from 18 to 29 years (mean: 22.3; SD: 3.17), while the yoked group's age ranged from 19 to 27 years (mean: 21.3; SD: 2.57). All participants had been diagnosed with DS and mild intellectual disability (IQ range: 50-70). Mental ages on the Stanford-Binet scale were available for 10 participants in the self-control group (mean: 6.3, SD: 0.94) and 11 participants in the yoked group (mean: 6.9, SD: 1.13), with a range from 5-8 in both groups. Exclusion criteria included a different intellectual disability level, diagnoses of autism, or other neurological disorder. Informed consent was obtained from the schools, the participants, and their parents/guardians. The study was approved by the Ethics Committee of Universidade Federal de Pelotas (UFPel), Pelotas, RS, Brazil (protocol number 056/2009). The task was novel to all participants, and they were unaware of the purpose of the experiment.

\section{Apparatus and task}

The task involved a linear positioning apparatus (Figure 1). It consisted of a straight slide bar, approximately $1 \mathrm{~m}$ in length, fastened to a sturdy base. A slide was attached to the slide bar. On one side, a measuring device secured to the base was used to measure the horizontal displacement of the slide. The slide could easily be moved side-to-side by hand. Participants sat on the side of the apparatus, opposite the measuring device, with their left shoulder in line with the starting position of the slide. Participants wore opaque swimming goggles to prevent the use of visual cues. They were asked to use their right hand to move the slide from the starting point, in one continuous motion, to their right toward the target. The target location for both the acquisition and retention phases was $60 \mathrm{~cm}$ from the starting point.

\section{Procedure}

Participants were assigned to either the self-control or yoked groups in a quasi-random order. Specifically, they were assigned to groups based on the chronological order of their appointment for participation, but were yoked male-to-male and female-to-female, with 7 men and 8 women in each group. Participants were informed about the goal of the task in simple language. They were asked to sit in a comfortable

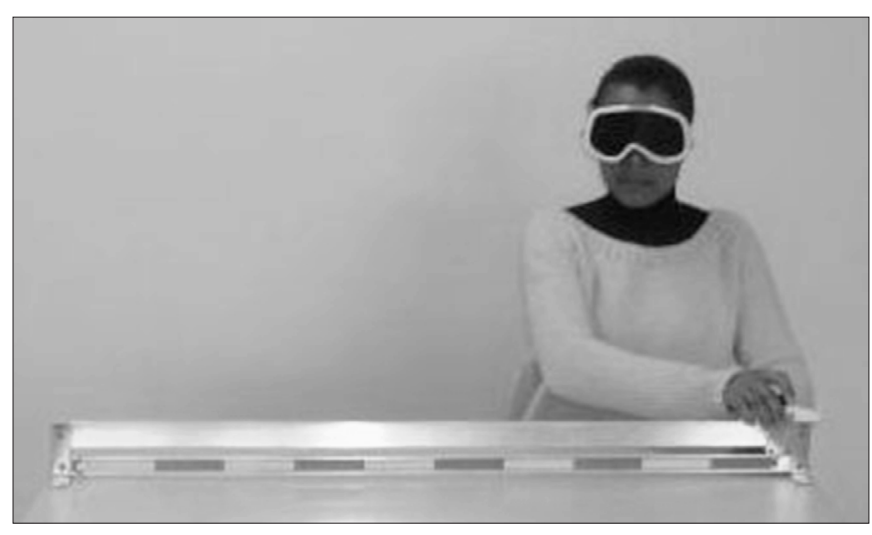

Figure 1. Photo of an individual, wearing opaque goggles, and the linear positioning apparatus.

position in front of the apparatus. The experimenter explained that they were to move the slide in one motion to the right from its starting position and attempt to stop it when it reached the target. The experimenter demonstrated the goal movement to them once to give them an idea of the target distance. Care was taken to ensure the participant understood the instructions and feedback to be provided. After the instructions, participants put on opaque swimming goggles to prevent visual feedback.

A trial ended when the participant removed his or her hand from the slide. After each trial, the experimenter returned the slide to the starting position. All participants performed 30 practice trials, with 10 seconds between trials. The feedback was qualitative in nature, i.e. participants were told "too short" or "too long" depending on the direction of the deviation from the target. No information about the actual distance from the target was provided. Self-control group participants were informed they would receive feedback only when they requested it. It was explained further that they were to request the feedback only when they thought they needed it, as they would eventually be asked to perform the task without the aid of feedback. Yoked group participants were told that they would receive feedback occasionally, and that they would eventually be asked to perform the task without feedback. Participants in the yoked group were each yoked to one participant in the self-control group. Thus, each yoked group participant received the same feedback frequency and schedule as the self-control group participant who preceded them. A retention test, performed on the following day, consisted of 10 trials without feedback.

\section{Data analysis}

Our dependent variable was absolute error (AE) measured in $\mathrm{cm}$. AE represents the absolute difference between 
the goal movement distance and actual distance (irrespective of error direction). Absolute error is an overall error measure that takes into account both movement accuracy and variability ${ }^{33}$. Accuracy scores on the 30 practice trials were averaged across blocks of 5 trials and analyzed in a 2 (group: self-control versus yoked) x 6 (blocks of 5 trials) analysis of variance (ANOVA) with repeated measures on the last factor. An additional analysis was performed to compare errors on feedback versus no-feedback trials during practice (i.e., to determine whether participants in the self-control group chose feedback primarily on relatively successful versus unsuccessful trials; see Chiviacowsky and Wulf $^{17}$; Chiviacowsky et al. ${ }^{31}$ ). For this purpose, a 2 (group: self-control versus yoked) x 2 (trial type: feedback versus no feedback) ANOVA was used. Retention data were analyzed in a 2 (group: self-control versus yoked) x 2 (blocks of 5 trials) ANOVA. This analysis was followed up by an analysis of covariance (ANCOVA), with the first practice trial as a covariate.

\section{Results $::$.}

\section{Practice}

Self-control group participants requested feedback after $31.3 \%$ of the practice trials, on average. The feedback frequency percentages for blocks 1-6 were 53.3, 40, 37.3, 30.7, 21.3 , and $6.7 \%$, respectively. Thus, participants consistently reduced their requests for feedback across practice.

Both groups reduced their AEs across blocks of trials (see Figure 2, left). The self-control group had generally smaller errors than the yoked group. The main effects of both block $\left[F(5,140)=9.37, \mathrm{p}<0.001, \eta^{2}=.25\right]$ and group $[F(1,28)=4.70$, $\left.\mathrm{p}<0.05, \eta^{2}=.14\right]$ were significant. The interaction between group and block was not significant $[F(5,140)<1]$.

AEs on feedback trials $(20.7 \mathrm{~cm})$ versus no-feedback trials $(21.8 \mathrm{~cm})$ were only slightly smaller for the self-control group, indicating that self-control participants did not chose feedback more after good trials than after poor trials. In contrast, participants in the yoked group tended to have somewhat larger errors on feedback trials $(25.9 \mathrm{~cm})$ relative to no-feedback trials $(24.5 \mathrm{~cm})$. However, the interaction of group and trial type was not significant, with $F(3,56)<1$.

\section{Retention}

The day following practice, a retention test (without feedback) revealed lower AEs for the self-control group than the yoked group (see Figure 2, right). The group difference

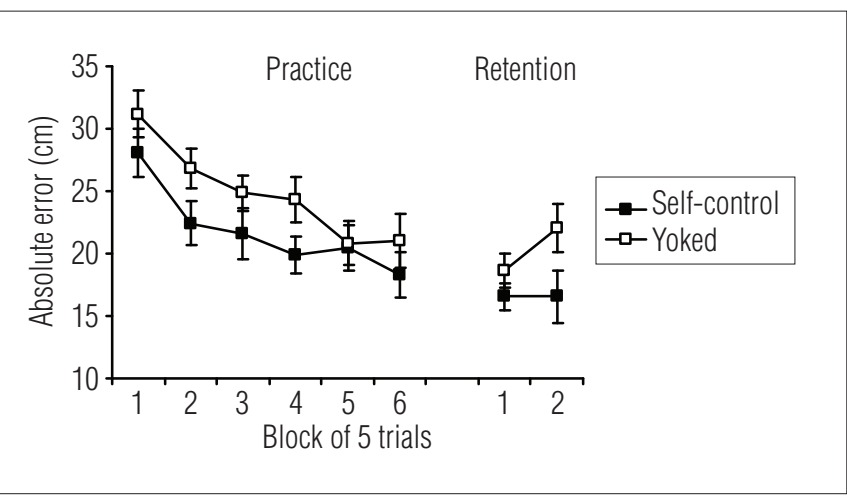

Figure 2. Accuracy scores of the self-control and yoked groups in practice and retention. Error bars represent standard errors.

was significant, with $F(1,28)=4.72, \mathrm{p}<0.05, \eta^{2}=.14$. The yoked group tended to demonstrate an increase in errors from Block 1 to Block 2, while the self-control group's performance remained stable, although neither the interaction of group and block $[F(1,28)=1.19, \mathrm{p}>0.05]$ nor the main effect of block $[F(1,28)=1.19, \mathrm{p}>0.05]$ were significant. Given the initial numerical difference in the groups' performances at the beginning of practice, we wanted to rule out the possibility that sampling error contributed to the group difference in retention. Therefore, we conducted an ANCOVA with the first trial as a covariate. The ANCOVA results indicated that the main effect of group in retention was still significant $\left[F(1,27)=6.49, \mathrm{p}<0.05, \eta^{2}=0.19\right]$. Thus, the opportunity to choose feedback enhanced the learning of the task.

\section{Discussion $: \because$.}

The purpose of the present study was to examine whether previously found benefits of self-controlled feedback ${ }^{17,19,31,32}$ would generalize to motor learning in people with DS. Adults with DS differ from unimpaired adults in various ways, including cognitive ${ }^{26}$ and motor aspects of performance ${ }^{3,34}$. Therefore, it was unclear whether they would show similar learning advantages to typical individuals when given the opportunity to decide how often and when to receive feedback.

The results of the present study showed that participants with DS indeed demonstrated more effective learning with self-controlled feedback compared with externally controlled feedback (yoked group). Thus, the present results are in line with those of previous feedback studies with unimpaired young adults ${ }^{17,19,32,35}$, older adults ${ }^{36}$, and children ${ }^{31}$. Self-control participants in the present study asked for feedback on a relatively small portion of trials (31.3\%), and they tended to choose a "fading" schedule, that is, they requested less and 
less feedback throughout practice. In previous studies, the percentage of trials with feedback was also relatively small (i.e., 35\% in Chiviacowsky and Wulf ${ }^{17}$; $7 \%$ Janelle, Kim and Singer ${ }^{18} ; 11 \%$ Janelle et al. ${ }^{19}$ ). These findings correspond with experimental findings showing that reduced feedback frequencies, and in particular fading schedules, are often more effective for learning than frequent feedback ${ }^{10}$ (for reviews, see Schmidt ${ }^{37}$ and Wulf and Shea ${ }^{38}$ ). Interestingly, the present findings showed that participants with DS also spontaneously chose a fading schedule - perhaps suggesting that they realized the potential risk of becoming dependent on the feedback if they requested it too frequently. However, this is a question that needs to be examined in future studies.

In contrast to previous studies ${ }^{17,31}$, self-control participants did not request feedback more frequently after relatively successful trials than after poor trials, as indicated by similar error scores on feedback and no-feedback trials. Interviews (with typical adults) conducted by Chiviacowsky and Wulf ${ }^{17}$ (see also Patterson and Carter ${ }^{32}$ ) indicated that participants (both self-control and yoked) preferred to receive feedback after good trials. In fact, subsequent studies demonstrated that learning was enhanced when feedback was provided after relatively good rather than poor trials ${ }^{39}$, presumably due to the enhanced intrinsic motivation resulting from "positive" feedback ${ }^{40-42}$. A preference for feedback after good trials was not evident for participants in the present study. One possible explanation for the fact that this effect was not replicated here is that the feedback in the present study was qualitative in nature (i.e., too short, too long), whereas participants in previous studies were provided with more specific, quantitative error information. Thus, the nature of the feedback may have made it more difficult for learners to develop a feel for "good" performances and to request feedback accordingly.

Interestingly, the fact that group differences in learning were still observed suggests that there are other factors that contribute to the learning benefits of self-controlled practice. It has been suggested that self-control facilitates learners' testing of different strategies, makes performers take charge of their own learning process, promotes deeper processing of relevant information, and might be more tailored to the learners' specific needs ${ }^{16}$. Another factor appears to be the learner autonomy inherent in self-controlled practice. Giving learners control over the practice conditions provides them with a certain degree of autonomy. Autonomy is seen as one of three fundamental psychological needs (in addition to competence and social relatedness) ${ }^{29,43}$, and refers to people's need to determine and have control of their own behavior.
Numerous studies have demonstrated the importance of autonomy for psychological well-being and optimal functioning, in general, and learning, in particular. For example, Cordova and Lepper ${ }^{44}$ found that children who worked with a higher level of autonomy showed increases in motivation, depth of engagement in learning, amount learned in a fixed time period, perceived competence, and levels of aspiration. Similarly, Zhou ${ }^{45}$ showed that individuals who worked in a high task-autonomy condition found more creative (novel and useful) solutions to problems than individuals in a low task-autonomy condition. Other studies have shown that, when autonomy is undermined, performance suffers, especially when flexibility and creativity are required ${ }^{46}$. Autonomy-supportive learning contexts enhance people's intrinsic motivation which, in turn, can lead to more effective learning outcomes ${ }^{29,30}$. In fact, some studies suggest that autonomy-supportive environments can potentially improve academic achievement in students with general learning disabilities ${ }^{47}$ and increase task persistence in persons with DS while working independently on challenging tasks ${ }^{48}$.

Thus, there is converging evidence that allowing learners to exert some control over the practice situation benefits learning. To our knowledge, the present study is the first to demonstrate that this effect is generalizable to motor learning in a population with an intellectual disability. These findings are important because they contrast with common practice in many applied settings, such as physical education or physical therapy, where teachers or clinicians tend to control most aspects of the practice session - including the provision of feedback - while the learner or patient assumes a relatively passive role. Yet, it is wellknown that passivity in the process of skill acquisition is detrimental to learning. Our findings are in line with the notion that human beings have fundamental psychological needs ${ }^{29,49}$. Evidently, this includes those who are mentally or physically challenged. Designing practice conditions in a way that they meet those needs would be expected to enhance the learning process. As the present study demonstrates, granting persons with DS autonomy with respect to the delivery of feedback benefited skill learning. This result is particularly important in light of the fact that persons with disabilities are often denied sufficient self-determination. Future studies should examine the generalizability of the learning benefits of self-controlled practice to more ecologically valid tasks in this population, as well as different variables controlled by the learner (e.g. presentation of a model demonstrating the skill, order of different tasks to be learned, use of assistive devices). 
1. Hassold T, Abruzzo M, Adkins K, Griffin D, Merrill M, Millie E, et al. Human aneuploidy: incidence, origin, and etiology. Environ Mol Mutagen. 1996;28(3):167-75.

2. Latash ML. Learning motor synergies by persons with Down syndrome. J Intellect Disabil Res. 2007;51(Pt 12):962-71.

3. Spanò M, Mercuri E, Randò T, Pantò T, Gagliano A, Henderson S, et al. Motor and perceptualmotor competence in children with Down syndrome: variation in performance with age. Eur $\mathrm{J}$ Paediatr Neurol. 1999;3(1):7-13.

4. Gupta S, Rao BK, Kumaran SD. Effect of strength and balance training in children with Down's syndrome: a randomized controlled trial. Clin Rehabil. 2011;25(5):425-32.

5. Bussy $G$, Charrin $E$, Brun $A$, Curie $A$, des Portes V. Implicit procedural learning in fragile $X$ and Down syndrome. J Intellect Disabil Res. 2011;55(5):521-8.

6. Almeida GL, Corcos DM, Latash ML. Practice and transfer effects during fast single-joint elbow movements in individuals with Down syndrome. Phys Ther. 1994;74(11):1000-12.

7. Cleland J, Timmins C, Wood SE, Hardcastle WJ, Wishart JG. Electropalatographic therapy for children and young people with Down's syndrome. Clin Linguist Phon. 2009;23(12):926-39

8. Wood S, Wishart J, Hardcastle W, Cleland J, Timmins C. The use of electropalatography (EPG) in the assessment and treatment of motor speech disorders in children with Down's syndrome: evidence from two case studies. Dev Neurorehabil. 2009;12(2):66-75.

9. Machado C, Chiviacowsky S, Marques A. Motor learning and Down syndrome: effects of the frequency of knowledge of results in motor skill learning. Proceedings of the $27^{\text {th }}$ National Congress of Physical Education, Rio Grande do Sul, Brasil; 2008.

10. Winstein CJ, Schmidt RA. Reduced frequency of knowledge of results enhances motor skill learning. J Exp Psychol: Learn Mem Cogn. 1990;16(4):677-91.

11. Bandura A. Self-efficacy: toward a unifying theory of behavioral change. Psychol Rev. 1977;84(2):191-215

12. Bandura A. Perceived self-efficacy in cognitive development and functioning. Educ Psychol. 1993;28(2):117-48.

13. Chen D, Singer RN. Self-regulation and cognitive strategies in sport participation. Int J Sport Psychol. 1992;23:277-300.

14. Zimmerman BJ, Ponz MM. Development of a structured interview for assessing student use of self-regulated learning strategies. Am Educ Res J. 1986;23(4):614-28.

15. Winne PH. Inherent details of self-regulated learning. Educ Psychol. 1995;30(4):173-87.

16. Wulf G. Self-controlled practice enhances motor learning: implications for physiotherapy. Physiotherapy. 2007;93(2):96-101.

17. Chiviacowsky S, Wulf G. Self-controlled feedback: does it enhance learning because performers get feedback when they need it? Res Q Exerc Sport. 2002;73(4):408-15

18. Janelle CM, Kim J, Singer RN. Subject-controlled performance feedback and learning of a closed motor skill. Percept Mot Skills. 1995;81(2):627-34.

19. Janelle CM, Barba DA, Frehlich SG, Tennant LK, Cauraugh JH. Maximizing performance feedback effectiveness through videotape replay and a self-controlled learning environment. Res Q Exerc Sport. 1997;68(4):269-79.

20. Wulf G, Clauss A, Shea CH, Whitacre CA. Benefits of self-control in dyad practice. Res $Q$ Exerc Sport. 2001;72(3):299-303.

21. Wulf G, Toole T. Physical assistance devices in complex motor skill learning: benefits of a selfcontrolled practice schedule. Res Q Exerc Sport. 1999;70(3):265-72.

22. Wulf $G$, Raupach $M$, Pfeiffer F. Self-controlled observational practice enhances learning. Res $Q$ Exerc Sport. 2005;76(1):107-11

23. Baddeley A, Jarrold C. Working memory and Down syndrome. J Intellect Disabil Res. 2007;:51(12):925-31

24. Vicari S, Marotta L, Carlesimo GA. Verbal short-term memory in Down's syndrome: an articulatory Ioop deficit? J Intellect Disabil Res. 2004:48(Pt 2):80-92.

25. Lincoln AJ, Courchesne E, Kilman BA, Galambos R. Neuropsychological correlates of information-processing by children with Down syndrome. Am J Ment Defic. 1985;89(4):403-14.
26. Silverman W. Down syndrome: cognitive phenotype. Ment Retard Dev Disabil Res Rev 2007;13(3):228-36.

27. Bogaerts $\mathrm{H}$, Swinnen SP. Spatial interactions during bimanual coordination patterns: the effect of directional compatibility. Motor Control. 2001;5(2):183-99.

28. Hodges NJ, Cunningham SJ, Lyons J, Kerr TL, Elliott D. Visual feedback processing and goaldirected movement in adults with Down Syndrome. Adapt Phys Activ Q. 1995;12(2):176-86.

29. Deci EL, Ryan RM. The "what" and "why" of goal pursuits: human needs and the self-determination of behavior. Psychol Inq. 2000;11(4):227-68.

30. Deci EL, Ryan RM. Self-determination theory: a macrotheory of human motivation, development, and health. Can Psychol. 2008;49(3):182-5

31. Chiviacowsky S, Wulf G, de Medeiros FL, Kaefer A, Tani G. Learning benefits of self-controlled knowledge of results in 10-year-old children. Res Q Exerc Sport. 2008;79(3):405-10.

32. Patterson JT, Carter M. Learner regulated knowledge of results during the acquisition of multiple timing goals. Hum Mov Sci. 2010;29(2):214-27.

33. Schmidt RA, Lee TD. Motor control and learning: A behavioral emphasis. $5^{\text {th }}$ ed. Champaign, IL: Human Kinetics; 2011.

34. Gomes MM, Barela JA. Postural control in down syndrome: the use of somatosensory and visual information to attenuate body sway. Motor Control. 2007;11(3):224-34.

35. Huet M, Camachon C, Fernandez L, Jacobs DM, Montagne G. Self-controlled concurrent feedback and the education of attention towards perceptual invariants. Hum Mov Sci. 2009;28(4):450-67.

36. Alcântara LB, Alves MA, Santos RCO, Medeiros LK, Gonçalves WR, Fialho JV, et al. Effects of self-controlled knowledge of results in motor learning of elderly adults. Brazilian Journal of Motor Behavior. 2007;2(1):22-30

37. Schmidt RA. Frequent augmented feedback can degrade learning: Evidence and interpretations In: Requin J, Stelmach GE (Eds.). Tutorials in motor neuroscience. Dordrecht, The Netherlands: Kluwer Academic Publishers; 1991. p. 59-75.

38. Wulf $\mathrm{G}$, Shea $\mathrm{CH}$. Understanding the role of augmented feedback: The good, the bad, and the ugly. In: Williams AM, Hodges NJ. (Eds.). Skill acquisition in sport: Research, theory and practice. London: Routledge; 2004. p. 121-44.

39. Chiviacowsky S, Wulf G. Feedback after good trials enhances learning. Res Q Exerc Sport. 2007;78(1):40-7

40. Badami R, VaezMousavi M, Wulf G, Namazizadeh M. Feedback after good versus poor trials enhances intrinsic motivation. Res Q Exerc Sport. 2011;82(2):360-4.

41. Wulf $G$, Lewthwaite R. Attentional and motivational influences on motor performance and learning In: A Mornell (Ed.). Art in Motion: Musical and Athletic Motor Learning and Performance. Frankfurt am Main: Peter Lang; 2009. p. 95-117.

42. Wulf $G$, Shea $C$, Lewthwaite $R$. Motor skill learning and performance: a review of influential factors. Med Edu. 2010;44:75-84.

43. Ryan RM, Deci EL. Self-determination theory and the facilitation of intrinsic motivation, social development, and well-being. Am Psychol. 2000;55(1):68-78.

44. Cordova DI, Lepper MR. Intrinsic motivation and the process of learning: beneficial effects of contextualization, personalization, and choice. J Educ Psychol. 1996;88(4):715-30.

45. Zhou J. Feedback valence, feedback style, task autonomy, and achievement orientation: interactive effects on creative performance. J Appl Psychol. 1998;83(2):261-76.

46. Utman CH. Performance effects of motivational state: a meta-analysis. Pers Soc Psychol Rev 1997;1(2):170-82

47. Deci EL, Hodges R, Pierson L, Tomassone J. Autonomy and competence as motivational factors in students with learning disabilities and emotional handicaps. J Learn Disabil. 1992;25(7):457-71.

48. Gilmore L, Cuskelly M, Jobling A, Hayes A. Maternal support for autonomy: relationships with persistence for children with Down syndrome and typically developing children. Res Dev Disabil. 2009;30(5):1023-33

49. Ryan RM, Deci EL. Active human nature: Self-determination theory and the promotion and maintenance of sport, exercise, and health. In: Hagger MS, Chatzisarantis NLD (Eds.). Intrinsic motivation and self-determination in exercise and sport. Champaign, IL: Human Kinetics; 2007. p. 1-19 